\title{
Novos desafios para o JBPML
}

Neste ano, novos desafios se anunciam para a diretoria científica recém-eleita da Sociedade Brasileira de Patologia Clínica/Medicina Laboratorial. Entre eles, não menos importante é o cuidado editorial com o seu principal veículo, o Jornal Brasileiro de Patologia e Medicina Laboratorial.

Uma revista científica se justifica em função de seu impacto sobre a comunidade a que se destina. Para essa avaliação são utilizados atualmente alguns parâmetros como velocidade de publicação dos artigos submetidos, periodicidade do veículo e sua indexação em índices bibliográficos, grau de impacto referente à citação de artigos por outros veículos, entre outros.

O Jornal Brasileiro de Patologia e Medicina Laboratorial conta com um histórico de progresso nos últimos oito anos. Esta trajetória foi marcada pela bem-sucedida associação com as Sociedades Brasileiras de Patologia e de Citopatologia, fazendo com que pudéssemos realmente concretizar uma publicação acadêmica de medicina laboratorial.

Neste caminho conseguimos, por mérito científico, indexar o JBPML no Scientific Electronic Library Online (SciElo), fazendo com que os artigos submetidos e aceitos para publicação pudessem ser contabilizados no rol da produção científica de instituições de renome, como as universidades federais e a Fundação Oswaldo Cruz. Dentro dessa mesma ótica de reconhecimento do mérito científico da revista, fomos agraciados com financiamento do Conselho Nacional de Desenvolvimento Científico e Tecnológico (CNPq) por dois anos consecutivos.

Estamos tratando na realidade de um veículo dinâmico, em que constantes mudanças são necessárias para a adaptação aos requisitos de alto padrão de agências financiadoras e de indexação. Nesse sentido, algumas mudanças ocorrerão no JBPML no decorrer de 2004.

A periodicidade da revista passará a ser bimestral, diminuindo-se o tempo entre a submissão e a publicação dos artigos. Temos como meta publicar neste ano pelo menos 60 artigos, o que nos colocaria no patamar de revistas de renome internacional. Os trabalhos que possam resultar em maior penetração no âmbito internacional serão publicados em inglês.

Estas alterações nos tornarão aptos a solicitar nossa indexação no PubMed e nos qualificarão para a inserção nas listas do Qualis da Coordenação de Aperfeiçoamento de Profissionais de Nível Superior (Capes). Assim, a produção científica inserida no JBPML passará a ser contabilizada nos cursos de pósgraduação reconhecidos nacionalmente.

Nosso editor, o dr. Octavio Fernandes, foi e tem sido peça fundamental para a marcante evolução da credibilidade científica do JBPML, por isso encontra-se mantido como tal na gestão que se inicia. Aos autores que aqui publicam, estejam certos da continuação de nossa trajetória de sucesso. 